\title{
"Kinetic and Thermodynamic study of uptake of methylene blue by crushed biomass of (Cicer arietinum as an adsorbent." Batch Study
}

\author{
A. A. Kale ${ }^{1}$, A.S.Burungale ${ }^{2}$, R.V. Kashalkar ${ }^{3}$ \\ ${ }^{1}$ S.M.Joshi College, Hadapsar, Pune 411028 \\ ${ }^{2} Y$. C. Institute of Science, Satara \\ ${ }^{3}$ T. R. Ingle Research Laboratory, S.P.College, Pune-411030 \\ Corresponding author ${ }^{\text {*: }}$ : A.A.Kale, S.M.Joshi College, Hadapsar, Pune 411028
}

\begin{abstract}
Present work deals with fundamental investigation on the adsorption of methylene blue by crushed biomass of Cicer arientinum is conducted in batch conditions. The effect of parameters such as contact time, sorbent dose, $\mathrm{pH}$ and temperature has been studied. Adsorption kinetic modeling data were found out. The kinetics of biosorption results shows that sorption process is well explained by pseudo-second order model with determination coefficients 0.980-0.992 for S-I under all experimental conditions. The value Kp is found to be 0.0498 The sorption mechanism was determined by Weber and Morris intraparticle diffusion model. Thermodynamic parameter viz $K D, \Delta G$ have also been calculated to determine the spontaneity of the process.
\end{abstract}

Key Word: Crushed Biomass S-I, Methylene Blue, Kinetic modeling, Thermodynamic Modelling.

\section{Introduction}

Contamination of the environment from a variety of sources has become an increasingly serious problem in recent years. The release of dyes into waste water by various industries posses, serious environmental problems due to their persistent and recalcitrant nature. The dye causes eye burns, which may be responsible for permanent injury to the eyes of humans and animals. If swallowed the dye causes irritation to the gastrointestinal tract with symptoms of nausea, vomiting, and diarrhea. It may also cause methemoglobinemia, cyanosis, convulsions, tachycardia, and dyspnea, if inhaled. It is likely to cause irritation to the skin. and are highly dangerous to biota. Dyes may also be problematic if they are broken down unaerobically in the sediments, as toxic amines are often produced due to incomplete degradation of bacteria. ${ }^{1}$ Some of the dyes or their metabolites are not only toxic or mutagenic but also carcinogenic. ${ }^{2}$ Synthetic dyes have complex aromatic structure which provides them physiochemical, thermal, biological and optical stability. ${ }^{3}$ The USEPA (Environmental Protection Agency) has classified textile wastes into four groups (1) dispersible (2) hard-to-treat (3) high volume (4) hazardous and toxic waste. ${ }^{4}$ Synthetic dyes are widely used in many industries including textile dyeing and paper printing. Color and dyes bearing waste water discharged into water streams not only contribute negatively to aesthetic value but also causes considerable resistance to biodegradation and may upset aquatic life ${ }^{5,5 a}$. Such colored waste water is unfit for recycling without proper treatment. Basic dyes are the brightest class of soluble dyes used by the textile industry ${ }^{6,7}$. Most dyestuffs are designed to be resistant to environmental conditions such as light, heat, microbial attack and also to oxidizing agent $^{8}$ making the biodegradation of dyes a very slow process. ${ }^{9}$ The conventional technologies used for the removal of dye stuffs include chemical coagulation/ flocculation, ozonation, membrane filtration, anaerobic degradation etc. These methods suffer from having low efficiency for reactive dyes and are also very expensive. These processes are therefore not very effective in treating waste water containing dyes. They are also not cost effective especially for developing countries ${ }^{\mathbf{1 0}}$. Currently, for such countries the most suitable technology in the removal of textile and other dyes seems to be adsorption.Literature also reports the removal of dyes such as Malachite green ${ }^{11,12}$, crystal violet, methyl red, Eriochrome Black T,deorlene,Saffranine red ${ }^{13}$ Acid orange -7, Acid red- 88 Acid blue113 methyl violet, onto different available adsorbents such as silica, alumina ${ }^{14}$ etc . However these adsorbents do not prove to be cost effective. The batch experiments have been carried out by S.P. Raghuvanshi. ${ }^{15}$ to study the kinetics of adsorption of methylene blue dye on bagasse with two different forms like raw and chemically activated forms. Spectrometric studies have been accomplished by A. Rasheed Khan for adsorption of dye methylene blue from aqueous solution on the surface of sheep wool and cotton fibre ${ }^{16}$ under optimal conditions of temperature , concentration, $\mathrm{pH}$, stay time duration and amount of adsorbent. Adsorbents prepared from sugarcane baggase an agro-industries waste have been successfully used to remove the dye methyl red from an aqueous solution in a batch reactor .These adsorbents have been investigated by S. Saiful Azhar by pretreating sugarcane baggase with formaldehyde and sulphuric acid. ${ }^{17}$ as sugarcane bagasse is a cheap and abundantly available biomass and adsorption is an ecofriendly and 
economically feasible dye- removal technique. ${ }^{18}$ From the related literature several biological materials have been reported as dye bioadsorbents, including banana and cotton fibre, ${ }^{11}$ orange fruit peels ${ }^{19}$, wheat bra $^{20-22}$ etc. A wide range of waste materials can be used as raw materials used for the new and novel adsorbents. Unconventional adsorbents like fly ash, bagasse, peat, lignite, wood, saw dust which fall into the above categories etc have therefore attracted the attention of several investigators. Adsorption characteristics of these materials have been widely investigated for removal of organic matter such as organic acids dyes ${ }^{6}$, phenol $^{23}$ refractory organic, heavy metals etc. The adsorption of dyes on these materials is reported to be fast and is completed within a short interval of time ${ }^{24-26}$. The study has been carried out mostly from the standpoint of the determination of adsorption isotherms and related parameters e.g particle size, surface area etc.

\section{Preparation of biosorbent and adsorbate solution:}

The stalks of Cicer arientinum were collected from Western Maharashtra, cleaned and shade dried. The dried material was crushed and used as biosorbent $\mathbf{S}-\mathbf{I}$ The solutions of methylene blue (3, 9 bis diamino phenathionium chloride) were prepared by dissolving appropriate amounts of dry powdered dye stuff in distilled water.Concentrations of the solutions used for this studies; were $0.799 \mathrm{mg} / \mathrm{L}$., $7.99 \mathrm{mg} / \mathrm{L}, 39.9 \mathrm{mg} / \mathrm{L}$ and $79.99 \mathrm{mg} / \mathrm{L}$.

\section{Experimental:}

Sorbent $50 \mathrm{mg}$ of was taken in different conical flasks, to each of these flasks $25 \mathrm{ml}$ of dye solution of initial concentration $(\mathrm{Co}=0.799 \mathrm{mg} / \mathrm{L})$ was added. The volume was made up to $100 \mathrm{ml}$ by adding distilled water. The flasks were protected from sunlight and stirred on magnetic stirrer for a period of $2,4,6,8,10,12,14,30$, and 60 minutes respectively and filtered through whatmann filter paper. The absorbence of the filterate was measured using systronic -112 photoelectric colorimeter at wavelength $640 \mathrm{~nm}$ filter. The same procedure mentioned above was used to study the effect of different variables mentioned.

\section{Effect of adsorbent dose:}

\section{Results And Discussion}

If sorbent dose of S-I is increased from $500 \mathrm{mg} / \mathrm{L}$ to $5.0 \mathrm{~g} / \mathrm{L}$ the maximum adsorption increases from $68.7 \%$ to $87.4 \%$. Although the $\%$ age removal increases with increase in the adsorbent dose, the adsorption capacity shows significant decrease at equilibrilium. For the dose of $5.0 \mathrm{~g} / \mathrm{L}$ the adsorption capacity is found to be $1.012 \mathrm{mg} / \mathrm{g}$, while it is $0.635 \mathrm{mg} / \mathrm{g}, 0.335 \mathrm{mg} / \mathrm{g}$ and $0.1334 \mathrm{mg} / \mathrm{g}$ for the doses of $500 \mathrm{mg} / \mathrm{L}, 1.0 \mathrm{~g} / \mathrm{L}, 2 . \mathrm{g} / \mathrm{L} \& 5.0$ g/L respectively (Fig. 1) The plots of adsorption capacity vs. time indicate that the smallest material dose 500 $\mathrm{mg} / \mathrm{L}$ equilibrium is attained after 14 minutes while for the highest dose $(5 \mathrm{gm} / \mathrm{L})$ equilibrium is attained within 5 minutes. These observations can be explained by considering the solute- sorbate interactions. When a solution is allowed to come in contact with an adsorbent the charged sorbate particles get attracted to the surface sites on the adsorbent particles. The extent of adsorption is directly proportional to the surface area available for adsorption. At a higher adsorbent dose there is an increase in the available surface area and also the number of available sites. This results in an increased and rapid uptake of the dye. However with increase in sorbent mass the amount of dye sorbed per unit mass of sorbent gets reduced thus causing a decrease in the adsorption capacity.

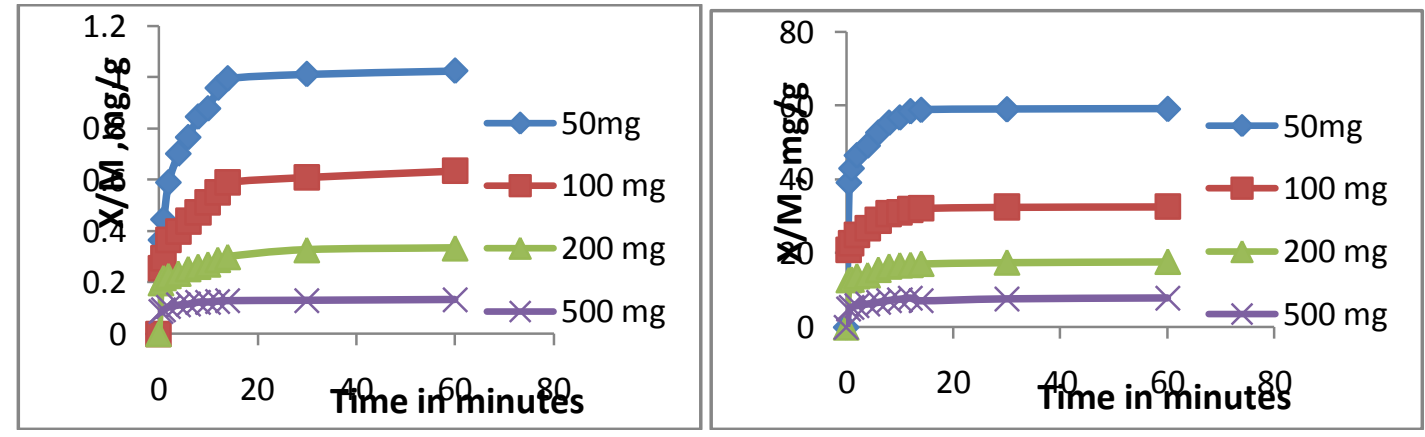

Fig.1 Plot of Adsorption capacity vs. time $(\mathrm{Co}=0.799 \mathrm{mg} / \mathrm{L} .79 .9 \mathrm{mg} / \mathrm{L})$

\section{Effect of Contact Time:}

The total amount adsorbed at equilibrium, more than $60 \%$ is seen to be adsorbed within the initial 2 minutes . The process reaches equilibrium within 30 minutes. The rate of adsorption decreases with time, probably due to saturation of the available sites. (Fig-2) The plot of \% adsorbed vs. time shows two distinct regions, one indicating rapid adsorption and the other indicating the slowed down rate. Equilibrium time is 15 to 
20 minutes for all concentration. Sorption is caused due to strong attractive forces between the dye molecules and the sorbent surface. The concentration of the dye at the surface of the sorbent differs from that in the solution, and therefore there exists a concentration gradient in the solution and at the surface. In the initial stage this gradient is large and leads to fast diffusion onto the external surface and the rate of adsorption is high. Then decrease in the concentration gradient and fast pore diffusion into the intra particular matrix and equilibrium is attained rapidly resulting into a slowed down rate of adsorption.

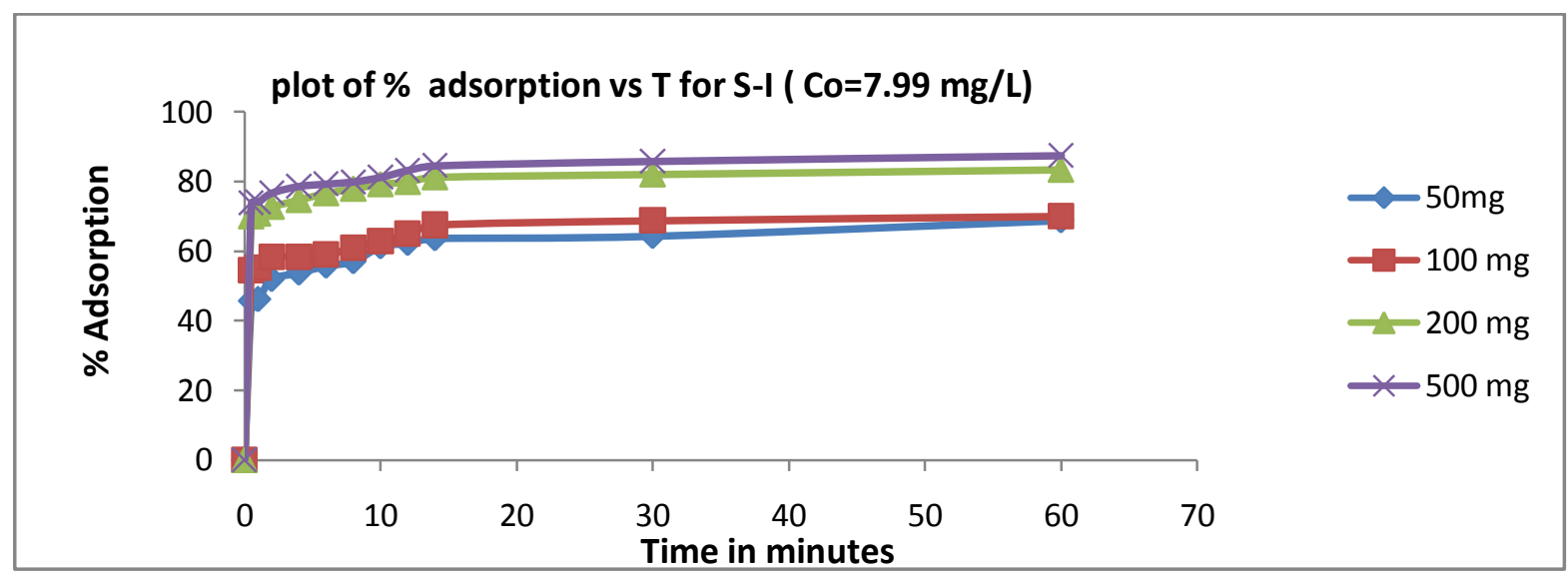

Fig.2 Plot of \% Adsorption vs. time S-I $(\mathrm{Co}=7.99 \mathrm{mg} / \mathrm{L})$

\section{Effect of pH:}

Plots of \% adsorption vs Time indicate that removal of the dye is insignificant in the $\mathrm{pH}$ range 6 to 10 . The amount adsorbed is maximum at $\mathrm{pH} 4$. A slight decrease is observed when the $\mathrm{pH}$ is raised from 4 to 6.These results indicate that the $\mathrm{pH}$ of the aqueous solution has a considerable effect on the both the binding sites of the sorbents and sorbate. The FTIR of the sorbent S-I shows that it contains different functional groups such as $-\mathrm{COOH},-\mathrm{OH}$ and other charged groups. The $\mathrm{pH}$ value of the supporting aqueous medium is likely to influence the dye adsorption properties at the solid liquid interface ${ }^{27}$. At low $\mathrm{pH}$ there are ample number of $\mathrm{H}^{+}$ ions along with the $[\mathrm{MB}]^{+}$ions and there is a competition between $\mathrm{H}^{+}$and $[\mathrm{MB}]^{+}$ions to occupy the adsorption sites of the sorbent. At a slightly higher $\mathrm{pH}$ the sorbate molecules are held by electrostatic attraction on the surface of the sorbent. Above $\mathrm{pH} 6$ there are ample number of $\mathrm{OH}$ ions in the solution leading to reduced adsorption of $[\mathrm{MB}]^{+}$on $\mathrm{S}-\mathrm{I}$ at higher $\mathrm{pH}$

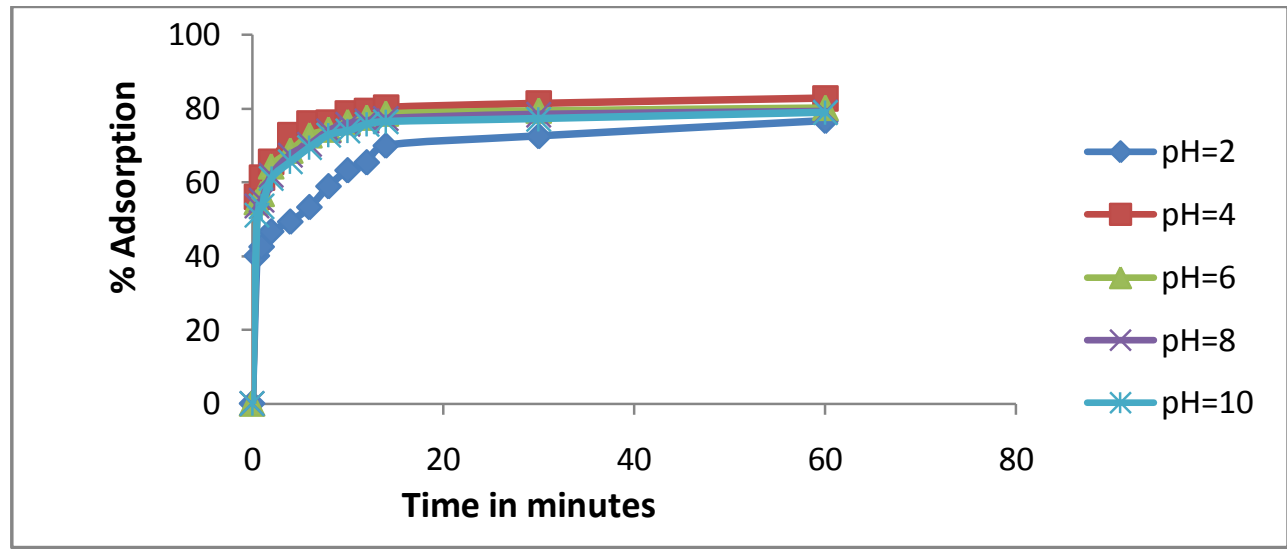

Fig.3 Effect of pH on \% adsorption of M.B. by S- I $(\mathrm{Co}=0.799 \mathrm{mg} / \mathrm{L})$

\section{Effect of Initial concentration}

For studying the effect dye on the process of adsorption the following concentrations have been chosen $0.799 \mathrm{mg} / \mathrm{L}, 7.99 \mathrm{mg} / \mathrm{L}, 39.9 \mathrm{mg} / \mathrm{L} \& 79.9 \mathrm{mg} / \mathrm{L}$ ). All the curves are smooth, single and continuous leading to saturation, suggesting monolayer formation of the dye on the sorbent surface Fig-4. The sorption capacity also increases with increase in initial dye concentration. The equilibrium sorption capacity is found to increase from 0.958 to $54.0 \mathrm{mg} / \mathrm{L}$ for the fixed sorbent dose of $500 \mathrm{mg} / \mathrm{L}$. During sorption the dye molecules initially reach the boundary layer and then have to diffuse into the sorbent surface and then into its porous structure. 


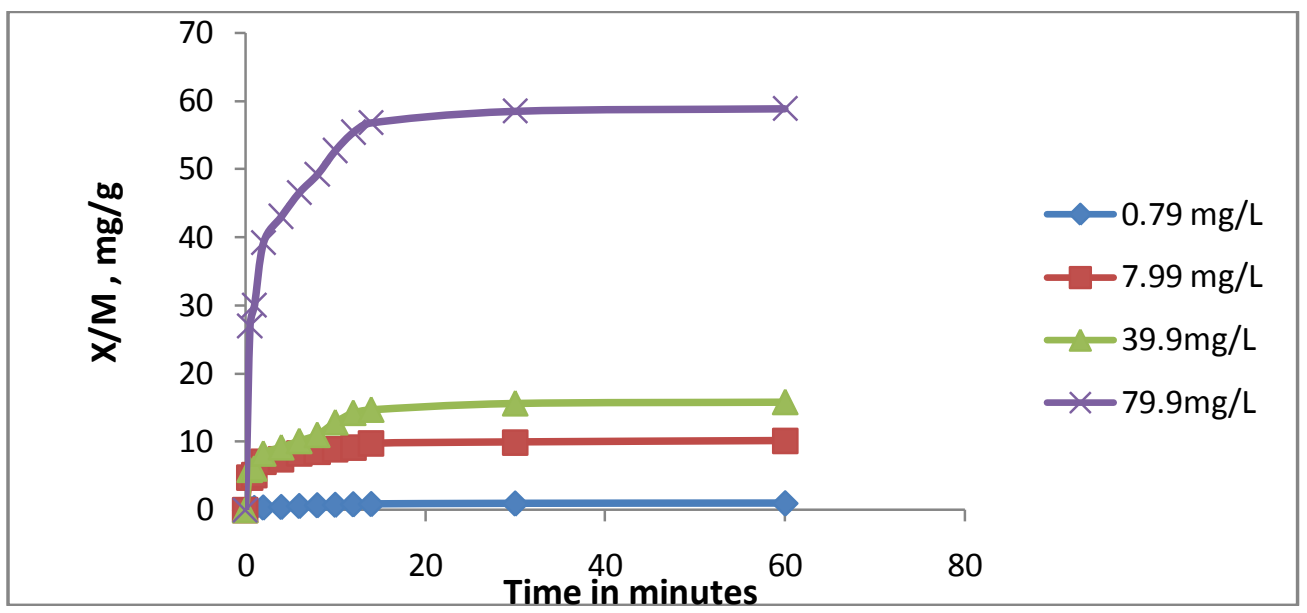

Fig- 4 Effect of initial concentration on removal of MB by S-I

\section{Langmuir Isotherm}

\section{Adsorption Equillibrium Modelling.}

The plots obtained are straight lines indicating the applicability of the Langmuir model. The correlation coefficient value is found to be 0.906 . The value of Langmuir constants a and $b$ are given below. The Hall separation factor RL is less than1, indicating favorable adsorption. These observations indicate a good fit of Langmuir model to adsorption by S-I in the concentration range studied. From this it can be concluded that there must be a monolayer adsorption of methylene blue on S-I.

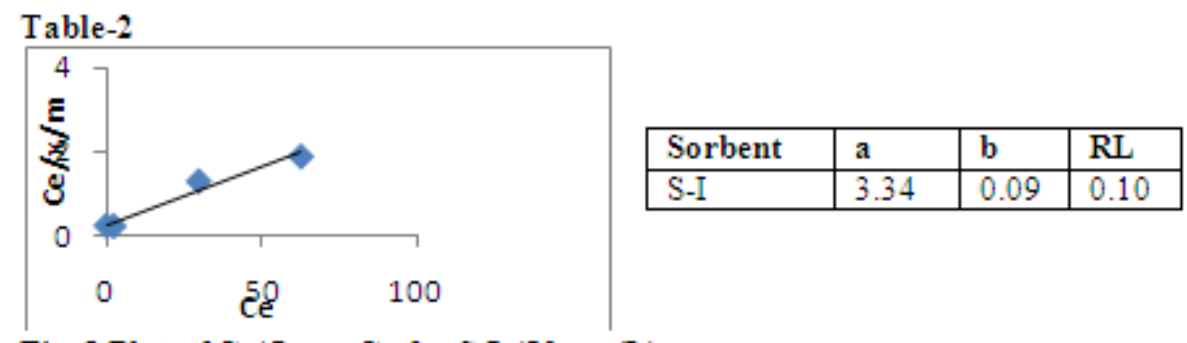

Fig. 8 Plot of Ce/Qe vs Ce for S-I $(50 \mathrm{mg} / \mathrm{L})$

\section{Freundlich isotherm model:}

The plot of $\log x / m$ vs. $\log C e$ is found to be a straight line with values of $K$ ranging between 4.4 to 7.907 in the temperature range of $15^{\circ} \mathrm{C}$ to $45^{\circ} \mathrm{C}$ and value of $\mathrm{n}$ between 1.26 tol.21. Increase in the values of $\mathrm{K}$ indicates that adsorption affinity increases with temperature showing favorable adsorption at higher temperature. According to Treybal (1980) if the value of $1 / \mathrm{n}$ lies between 0.1 to 1.0 it corresponds to beneficial adsorption. If the value of $1 / \mathrm{n}$ is less than unity it indicates better adsorption and formation of relatively stronger bonds between adsorbent and adsorbates.

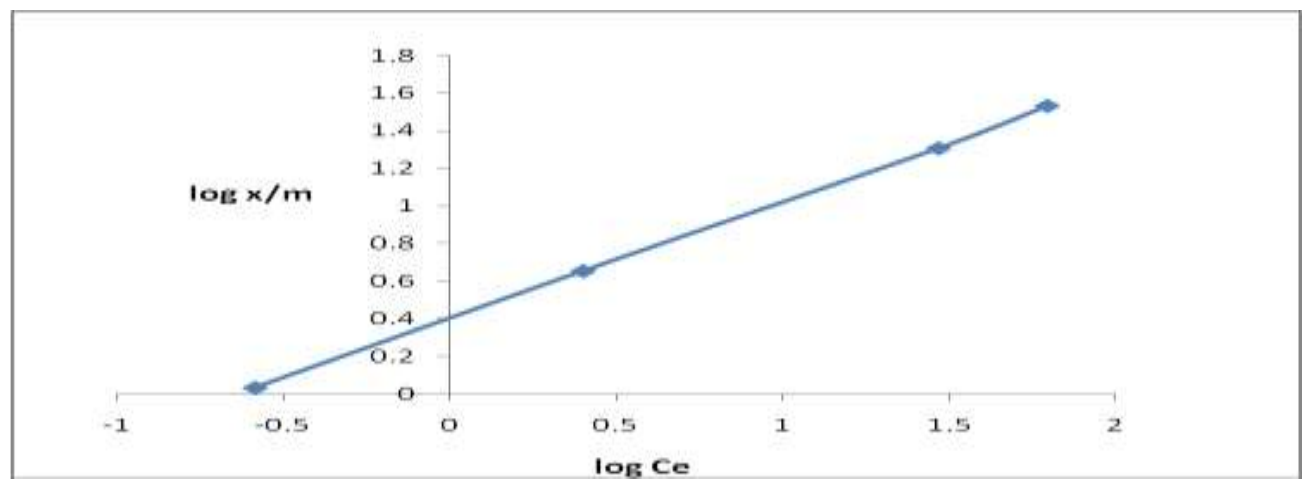

Fig-9 A graph of $\log$ Ce vs $\log \mathbf{x} / \mathrm{m}$ for $50 \mathrm{mg}$ S-I 
Thermodynamic parameter:

The equillibrium constant $\mathrm{K}$ for the process of adsorption can be used to calcualte the change in standared free energy using the relation

$\square \mathrm{G}=-\mathrm{RT} \ln \mathrm{K}$, where $\mathrm{K}$ is the equillibrium constant, it can be determined as

$\mathrm{A}+$ dye $=\mathrm{A}$-dye compelx, $\mathrm{A}$ is the adsorbent

Therfore

$$
\text { concentration of dye present on the surface }
$$

$$
\mathrm{KD}=
$$

$$
\text { remaining concentration in solution }
$$

Table-3

\begin{tabular}{|l|l|l|}
\hline Initial concentration & KD & $\Delta \mathrm{G}$ \\
\hline $0.799 \mathrm{mg} / \mathrm{L}$ & 2.08 & -1814.8 \\
\hline $7.99 \mathrm{mg} / \mathrm{L}$ & 2.166 & -1915.20 \\
\hline $39.9 \mathrm{mg} / \mathrm{L}$ & 0.3518 & +2588.70 \\
\hline $79.9 \mathrm{mg} / \mathrm{L}$ & 0.2717 & +3219.80 \\
\hline
\end{tabular}

The values of $\mathrm{KD}$ are found to vary with the initial concentration. For the lower concentration the free energy values are negative indicating the spontaneity of the process. As the initial concentration increases above $7.99 \mathrm{mg} / \mathrm{L} \mathrm{KD}$ falls drastically probably due to the saturation of the sites, the $\Delta \mathrm{G}$ also becomes positive

\section{Kinetic Modeling}

The data obtained was fitted in the Lagergren first order and the pseudo second order equations. The plots of ( $\log$ qe-qt) $v s . t$ for all values of amount of adsobate and initial concentration (Co) are shown in the fig. 10. As seen in the plots and from $\mathrm{R}^{2}$ values it appears that the pseudo first model cannot describe the sorption kinetics of the dye studied. The linear regression of the observed values lines with coefficients of determination ranging from 0.97 to .91.for lower values of initial concentration, while for higher initial concentration $\mathrm{R}^{2}$ ranges between 0.928 to 0.721 . These observations lend support that the model doesn't help to explain the kinetics of adsorption on S-I. The pseudo second order equation was applied by Ho \& McKay. The plots of t/qt vs. $t$ are straight lines. With coefficient of determination between 0.980 and 0.992, Fig.11.
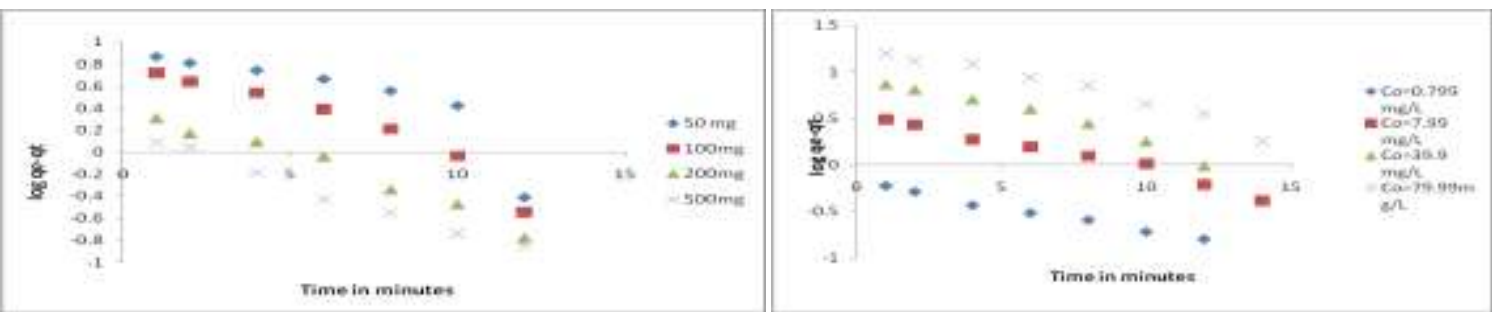

Fig. $10 \log$ qe-qt vs. $t$ for $\mathrm{S}-\mathrm{I}$ (varying sorbent dose, varying initial concentration)

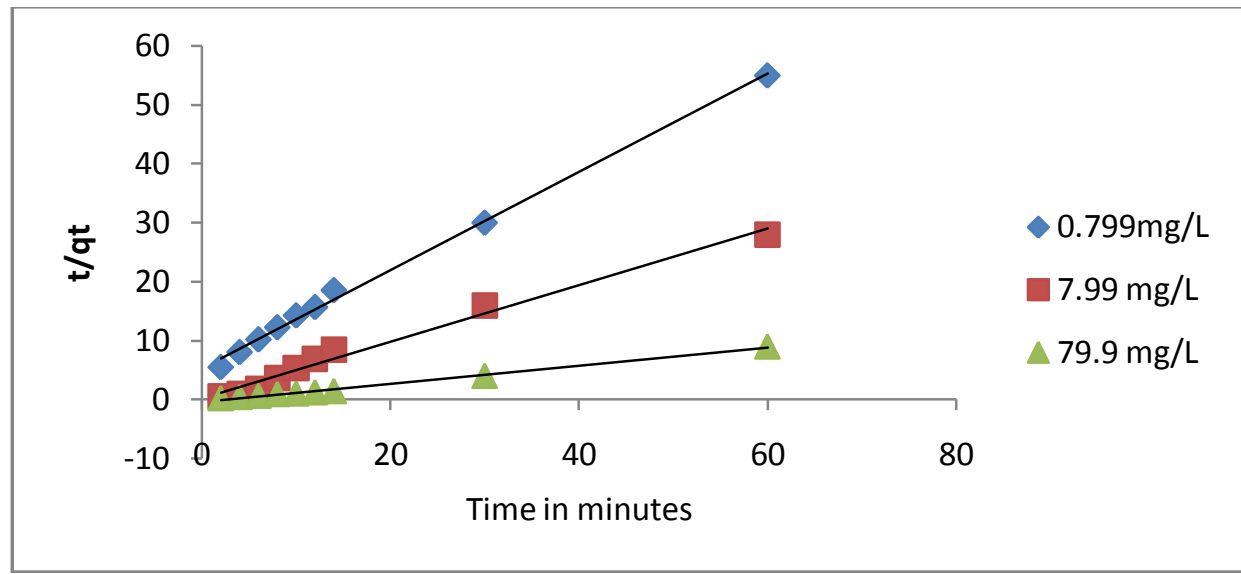

Fig. 11 Graph of t/qt vs. $t$ for $S-I(50 \mathrm{mg}, \mathrm{Co}=0.799 \mathrm{mg} / \mathrm{L}, 7.99 \mathrm{mg} / \mathrm{L}$ and $79.9 \mathrm{mg} / \mathrm{L})$ 


\section{Intraparticle Studies.}

The plots of Q vs. $t^{1 / 2}$ show three distinct regions, the first portion indicating mass transfer while the final portion indicates intraparticle diffusion. The intercept of the final linear portion indicates the boundary layer effect. The value $\mathrm{Kp}$ is found to be 0.0498 while the intercept has a value 0.51 . The value of the intercept increases with initial concentration indicating that boundary layer effect increases with concentration.

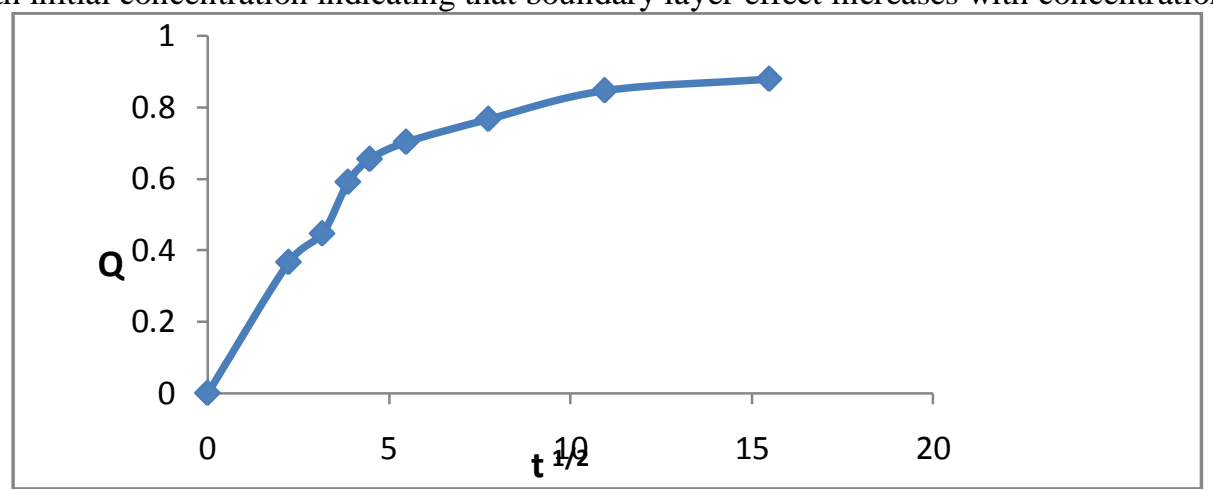

Fig.-12 A) Plot of $Q$ vs. $\mathrm{t}^{1 / 2}$ for $50 \mathrm{mg} \mathrm{S-I}(\mathrm{Co}=0.799 \mathrm{mg} / \mathrm{L})$

\section{Acknowledgement:}

I sincerely thanks to principal Dr. A.S.Burungale, and Dr. M.M.Rajmane for inspiration to my research work.

\section{References}

[1] E. Weber, N.L. Wolfe, Environ .Toxicol.Chem. 6,911-920, 1987

[2] R.Sivaraj, C.Namasivayam, K.Kadirvelu, Waste Management, 21, 105-110, 2001

[3] G.Mckay, J.Chem.Technol.Biotechnol. 32,759-772, 1982

[4] M.Arami, N.Yousefi Limaee, N.M. Mahmoodi, N.S. Tabrizi, J.Colloid Interface Sci., 288,371-376. 2005

[5] Mishra, G. and Tripathy, M. Colourage 40, 35. 1993

[6] R.C.Kapoor, S.L. Kalani., J. Indian Chemical Society, Vol, XI, PP.600-603. July 1984,

[7] R. Reid, J. Soc. Dyes Colour, 112, 103-109. 1996

[8] Pagga, U.M. and Taeger, K., Water Resour. Res. 28, 1051, 1994

[9] O’ Mahony, T. , Guibal, E. and Tobin, J.M., Enzyme Microbial Technol. 31, 456, 2002

[10] 10. Bousher A., Shen, X and Edyvean, R.G.J., Water Res.31, 2084, 1997

[11] D.Mall and Upadhyaya IndianJ Environmental Health, Vol.40 No: 2 177-188, 1998

[12] Madhavi Deshmukh, R.V.Kashalkar and N.R. Deshpande Asian J. of Chemistry Vol.16 No.3, 1863-1867, 2004

[13] GordanMcKay\&bushra Al- Durl, Colorage Annual, pages 23-28, 1989-90

[14] Raj Singh, B.B.Prasad., Indian National Science academy, Vol. 41 Part A, No.2, 163-169, 1975.

[15] S.P. Raghuvanshi, R. Singh, C.P.Kaushik, Applied Ecology and Environmental Research,2 (2), 35-43,ISSN 1589-1623,2004

[16] A. Rasheed Khan, Hajira Tahir, Fahim Uddin, UzmaHameed, J. Appl. Sci. Environ. Mgt., Vol. 9 (2), 29-35., 2005.

[17] S. Saiful Azhar, A.Ghaniey Liew, D. Suhardy, American Journal of applied Sciences 2 (11), 1499-1503, 2005.

[18] Churchley, J. H. , Greaves, A. J., Hutchings, M. G., Games, A.E. and Phillips , D.A.S, Water Res. 34, 1673. 2000

[19] Annadurai, G., Ruey, S.J.and Duu, J.L,J. Hazard. Mater. 92,263. 2002.

[20] Oualid Hamdaoui, Mahdi Chiha Acta Chem Slov. 54, pp. 407-418, 2007.

[21] D.Ghosh, K.G. Bhattacharyya, Appl. Clay Sci., 20, 295-300, 2002

[22] Sharma, P., Kumari, P., Srivastava, M.M. and Srivastava, Shalini. Bioresource Technology, 98, 474-477; 2007.

[23] S. Mahesh Desh Deepak Indian Journal of Environ.Hlth. Vol.40, No.2, 169-176. 1998

[24] R.N.Ram and B.B.Prasad, Indian Journal of Chem.24A, 24-27, 1985

[25] C.H.Giles and A.P. D'silva, Trans - Faraday Soc.65, 25-26, 1996

[26] J.W.Calbraith, C.H.Giles, A.G.Halliday, A.S.A.Hassan, D.C.Mcallistc, N.Macaulay and W.J.Macmillan, J.Appl.chem.,8,416. 1958 